\title{
Kinetics of Oxidation of Tryptophan by Sodium Hypochlorite
}

\author{
Thomas Rausch, Frieder Hofmann, and Willy Hilgenberg* \\ Botanisches Institut der Johann-Wolfgang-von-Goethe-Universität, \\ Siesmayerstraße 70, D-6000 Frankfurt
}

Z. Naturforsch. 36 b, 359-361 (1981); received September 12, 1980

Tryptophan, Indoleacetaldehyde, Amino Acid Oxidation, Sodium Hypochlorite, Reaction Kinetics

\begin{abstract}
The oxidation of tryptophan to 3 -indoleacetaldehyde with sodium hypochlorite was investigated with ${ }^{14} \mathrm{C}$ labelled DL-tryptophan. The reaction was performed under pseudo first order conditions. From the $\mathrm{pH}$ dependence of the reaction it was concluded that only the unprotonated tryptophan is converted to the aldehyde. The activation energy is $35 \pm 2.2(\mathrm{SE}) \mathrm{kJ} \times \mathrm{mol}^{-1}$ as derived from the Arrhenius plot. Variing the $\mathrm{pH}$ between 8.5 and 11.0 and the temperature in the range from $298 \mathrm{~K}$ to $318 \mathrm{~K}$ did not alter the selectivity of the reaction as confirmed by TLC of the product (purity $\geqq 90 \%$ ).
\end{abstract}

A possible reaction mechanism is proposed.

\section{Introduction}

Several kinetic investigations on amino acid oxidation have been performed [1-3]. Depending on the nature of the oxidant these authors report different products involving different reaction mechanisms. In this study sodium hypochlorite was used for the oxidation of the aromatic amino acid tryptophan. Under slight alkaline conditions 3indoleacetaldehyde is the major oxidation product [4]. Under our experimental conditions this reaction was highly selective, so it was possible to investigate the reaction kinetics.

\section{Materials and Methods}

Materials: DL-tryptophan (side-chain-3-14C), specific activity $48 \mathrm{mCi} / \mathrm{mmol}$ (New England Nuclear); 3 -indolyl-(2-14C)-acetic acid, specific activity 25 to $35 \mathrm{mCi} / \mathrm{mmol}$ (CEA); 3-indoleacetaldehyde $\times$ $\mathrm{NAHSO}_{3}$ (Sigma); indole-3-ethanol (Sigma); 3indoleacetaldoxime, synthesized according to [5]; $5.2 \% \mathrm{NaOCl}$ solution (Merck).

General procedure: $500 \mu \mathrm{l}$ of an aqueous $10 \mathrm{mM}$ try solution (adjustment to desired $\mathrm{pH}$ by either $1 \mathrm{~N} \mathrm{HCl}$ or $1 \mathrm{~N} \mathrm{NaOH}$ ) including $200 \mathrm{nCi}$ of ${ }^{14} \mathrm{C}$ labelled try are overlayered with $10 \mathrm{ml}$ of redistilled benzene. The cylindrical reaction vessel $(25 \times$ $100 \mathrm{~mm}$ ) is fixed in a waterbath and the two layers are thoroughly mixed by a magnetic stirrer. The reaction is started by the addition of $4 \mu \mathrm{l}$ of a $0.5 \%$ $\mathrm{NaOCl}$ solution of the same $\mathrm{pH}$ as the reaction mixture; the same amount of $\mathrm{NaOCl}$ solution is

\footnotetext{
* Reprint requests to Prof. Dr. W. Hilgenberg. 0340-5087/81/0300-0359/\$01.00/0
}

Abbreviations: IAAld $=3$-indoleacetaldehyde, $\mathrm{RFE}=$ rotary film evaporation, TLC = thin layer chromatography, try = tryptophan. supplied at one minute intervals throughout the reaction time. Every $5 \mathrm{~min}$ a $0.5 \mathrm{ml}$ sample of the benzene layer is taken for determination of its radioactivity and replaced by fresh benzene. At the end of the reaction the benzene layer is pipetted off.

Identification and quantification of the reaction product: For determination of purity the benzene phase is dried on $\mathrm{Na}_{2} \mathrm{SO}_{4}$ and its volume reduced by RFE. Aliquots equivalent to $50 \mathrm{nmol}$ IAAld are submitted to TLC in 2 different systems:

1. Silicagel $\mathrm{F}_{254}$ on alufoil (Merck); solvent system chloroform: methanol $(96: 4)$.

2. Cellulose $\mathbf{F}_{254}$ on alufoil (Merck); solvent system water: methanol $(99: 1)$.

The product is identified by cochromatography with authentic IAAld and localized by both its fluorescence quench at $254 \mathrm{~nm}$ and its colour reaction with Ehmann's reagent [6]. To determine the distribution of radioactivity non sprayed chromatograms are cut horizontally into $0.5 \mathrm{~cm}$ stripes and their radioactivity is determined by liquid scintillation counting.

Derivatization of the product: For the conversion to indole-3-ethanol an aliquot of the dried benzene phase is evaporated by RFE over $1 \mathrm{ml} 1 \mathrm{M} \mathrm{NaBH}_{4}$ and the reaction is allowed to proceed for additional $10 \mathrm{~min}$. The reaction mixture is extracted twice with $10 \mathrm{ml}$ benzene and the combined benzene phases are dried on $\mathrm{Na}_{2} \mathrm{SO}_{4}$. After volume reduction by RFE aliquots equivalent to $50 \mathrm{nmol}$ indole-3. ethanol are chromatographed in the TLC systems already described. Identification with authentic indole-3-ethanol and quantification follow the procedure described for IAAld.

The conversion to 3 -indoleacetic acid is carried out by oxidation of IAAld with $\operatorname{Ag}_{2} \mathrm{O}$. Aliquots of the dried benzene phase containing additionally variing amounts of unlabelled IAAld are evaporated to dryness by RFE. $2 \mathrm{ml} 20 \mathrm{mM} \mathrm{AgNO} 3$ of different 
$\mathrm{pH}$ values (range 8.0 to 13.0 ) are added. The reaction time is varied between 0.5 and $90 \mathrm{~min}$. The reaction is stopped by adjusting the reaction mixture to $\mathrm{pH} 2.5$ with $1 \mathrm{M} \mathrm{H}_{2} \mathrm{SO}_{4}$. The reaction products are extracted twice with $10 \mathrm{ml}$ of diethylether. TLC, identification and quantification follow the procedure described for IAAld.

To form the bisulfite addition product the crude benzene phase is washed with $0.1 \mathrm{M}$ potassium phosphate buffer, $\mathrm{pH} 7.0$ and evaporated by RFE over $1 \mathrm{ml} 50 \mathrm{mM} \mathrm{NaHSO}_{3}, \mathrm{pH} 7.0$. Non-bound radioactive compounds are reextracted with fresh benzene. Liberation of IAAld from the bisulfite addition product is performed by adding $1 \mathrm{M}$ sodium carbonate, $\mathrm{pH} 10.0$ followed by extraction with fresh benzene.

\section{Results and Discussion}

\section{Reaction order}

As the oxidant was supplied continuously the reaction order was expected to be first order. The graphical determination of the reaction order confirmed this assumption (Fig. 1). For all experiment variants more than $90 \%$ of the reaction products cochromatographed with authentic IAAld in two TCL systems demonstrate that the aldehyde is the only benzene soluble product.

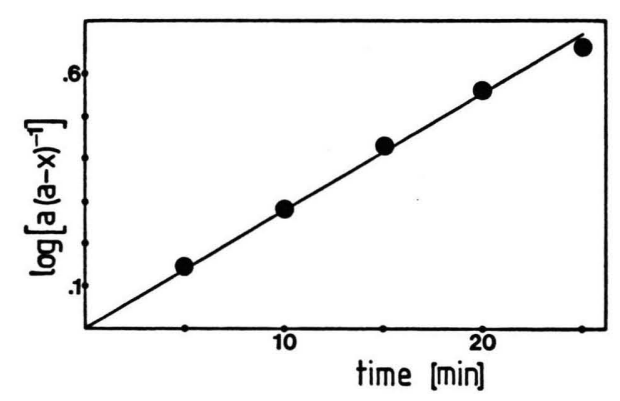

Fig. 1. Determination of reaction order. Initial tryptophan concentration: $10 \mathrm{mM}$; temperature: $45^{\circ} \mathrm{C}$; $\mathrm{pH}$ 10.0. a, initial radioactivity of tryptophan

$\left(4.4 \times 10^{5} \mathrm{dpm}\right) ; \mathrm{x}$, actual radioactivity of indoleacetaldehyde.

\section{2. $p H$ Dependence of the reaction}

Variing the $\mathrm{pH}$ in the range from 8.5 to 11.0 did not alter the selectivity of the reaction as concluded from TLC of the dried benzene phase. The initial reaction rate is directly proportional to the concentration of the unprotonated try suggesting that only the unprotonated amino acid is oxidized (Fig. 2).

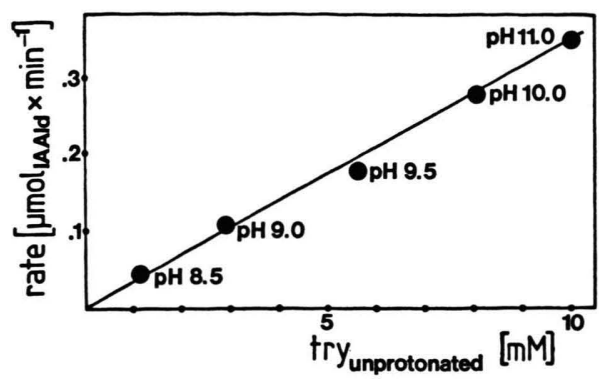

Fig. 2. Dependence of initial rate on unprotonated tryptophan concentration. Initial tryptophan concentration (total) $10 \mathrm{mM}$. Unprotonated tryptophan concentration at different $\mathrm{pH}$ values calculated from the pK value of the amino group (9.39).

\section{Temperature dependence of the reaction}

The selectivity of the reaction was not impaired when varying the temperature between $298 \mathrm{~K}$ and $318 \mathrm{~K}$. The activation energy is $35 \pm 2.2$ (SE) $\mathrm{kJ} \cdot \mathrm{mol}^{-1}$ as calculated from the Arrhenius plot (Fig. 3).

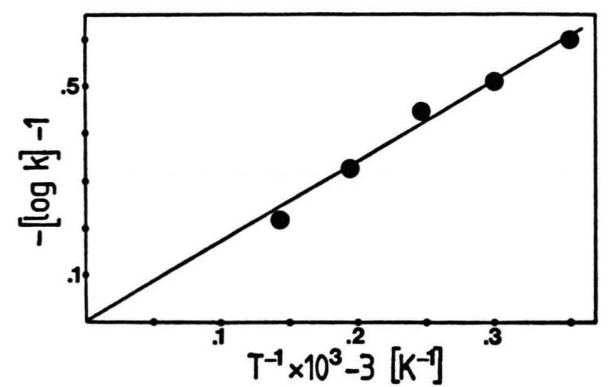

Fig. 3. Arrhenius plot. Initial tryptophan concentration: $10 \mathrm{mM}$; $\mathrm{pH} 10.0$.

\section{Evidence against a radical mechanism}

The oxidant $\mathrm{NaOCl}$ is in a $\mathrm{pH}$ dependent equilibrium with $\mathrm{HOCl}$. The latter may readily disproportion to $\mathrm{HCl}$ and oxygen radicals. If oxygen or $\mathrm{OH}$-radicals (which are formed subsequently in aqueous solution) were the oxydizing agents the addition of compounds known to scavenge these radicals should decrease the reaction rate [3]. However, adding mannitol in excess (1 M) did not influence the reaction rate significantly (control: rate $320 \mathrm{nmol} \cdot \mathrm{min}^{-1} ; \quad+1 \mathrm{M}$ mannitol $=$ rate $\left.350 \mathrm{nmol} \cdot \mathrm{min}^{-1}\right)$. This result and the high selectivity of the reaction suggest that $\mathrm{OCl}^{-}$ions are the more likely oxidant.

\section{Identification of the reaction products}

The identity of the aldehyde was confirmed as follows: 
a) More than $90 \%$ of the radioactivity of the benzene phase could be reversibly bound to $\mathrm{NaHSO}_{3}$ indicating the formation of the bisulfite addition product,

b) in 2 TLC systems more than $90 \%$ of the radioactivity cochromatographed with authentic commercially available IAAld,

c) after derivatisation with $\mathrm{NaBH}_{4} 95 \%$ of the radioactivity cochromatographed with authentic commercially available indole-3-ethanol,

d) the derivatisation to 3 -indoleacetic acid was attempted by oxidation with $\mathrm{Ag}_{2} \mathrm{O}$ yielding a variety of labelled compounds one of which cochromatographed with authentic 3 -indoleacetic acid (varying the parameters reaction time and $\mathrm{pH}$ did not improve the conversion to 3 -indoleacetic acid; however, the spectrum of oxidation products was the same when commercially available unlabelled IAAld or 3 -indolyl-(2-14C)-acetic acid were submitted to the same procedure).

$25 \%$ of the major impurity (accounting for up to $6 \%$ of the radioactivity in the benzene phase) could be converted to IAAld simply by stirring the compound in benzene over sodium carbonate buffer, $\mathrm{pH} 10.0$ at $45^{\circ} \mathrm{C}$. The compound cochromatographed with authentic indoleacetaldoxime which is readily hydrolyzed to the aldehyde under these

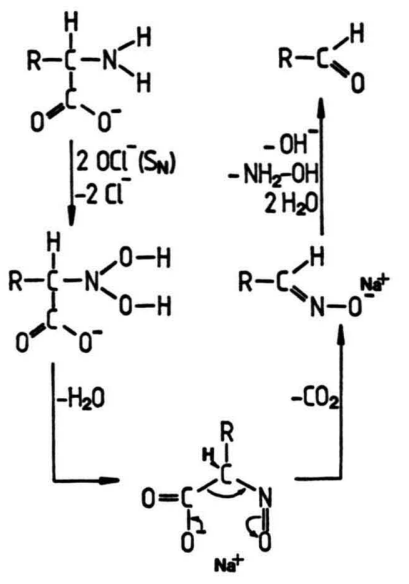

conditions. Hence 3-indoleacetaldoxime is a postulated intermediate in the proposed reaction mechanism.

\section{Proposed reaction mechanism}

The initial step could be a nucleophil substitution between the unprotonated amino group and $2 \mathrm{OCl}^{-}$ ions similar to the initial step proposed by Gowda and Mahadevappa [2] who used Chloramine-T as the oxidant. After dehydration and decarboxylation the aldoxime would be formed which under our experimental conditions hydrolyzes to the aldehyde.
[1] M. Bhargava, B. Sethuram, and T. Navaneeth Rao, Indian J. Chem. 16 A, 651 (1978).

[2] N. M. M. Gowda and D. S. Mahadevappa, Monatsh. Chem. 110, 157 (1979).

[3] R. Straight and J. D. Spikes, Photochem. Photobiol. 27, 565 (1978).
[4] R. A. Gray, Arch. Biochem. Biophys. 81, 480 (1959).

[5] A. Ahmad, I. Eelnurme, and I. D. Spenser, Can. J. Chem. 38, 2523 (1960).

[6] A. Ehmann, J. Chromatogr. 132, 267 (1977). 